\title{
Customer Experience and Determinants of Consumer Attitude Toward Luxury Brands: Observations in Japan and China
}

\author{
Ken Kumagai ${ }^{1,2}$, Shin'ya Nagasawa ${ }^{2}$ \\ ${ }^{1}$ Cross Company Inc., Okayama, Japan \\ ${ }^{2}$ Graduate School of Commerce, Waseda University, Tokyo, Japan
}

Email address:

k-kumagai@crosscompany.co.jp (K. Kumagai), nagasawa@waseda.jp (S. Nagasawa)

\section{To cite this article:}

Ken Kumagai, Shin'ya Nagasawa. Customer Experience and Determinants of Consumer Attitude Toward Luxury Brands: Observations in Japan And China. Science Journal of Business and Management. Special Issue: Customer Experience Management/MarketingBranding. Vol. 3, No. 2-1, 2015, pp. 24-34. doi: 10.11648/j.sjbm.s.2015030201.13

\begin{abstract}
This study extends Kumagai and Nagasawa's (2015) discussion on consumer attitude toward luxury brands by conducting consumer research in Japan and China. It focuses on eight luxury brands-Ralph Lauren and Armani, Coach and Louis Vuitton, Tiffany and Cartier, and Cadillac and Mercedes Benz-in four product categories - apparel, leather goods, jewelry, and automobile, respectively. The determinants of consumer attitude and customer experience are discussed between the two countries and across the four categories. Customer experience is examined using a strategic experiential module (SEM). The multivariate statistics and discussion in this paper provide the following five implications. (1) Chinese consumer perception of luxury brands is generally similar to that of the Japanese. (2) Japanese and Chinese consumers' attitude toward luxury brands, to some degree, is determined on the basis of three factors: perceived esthetics, perceived orthodoxy, and perceived rarity. The impact of perceived rarity on consumer attitude differs between Japan and China. (3) Perceived esthetics and orthodoxy have positive impacts on consumer brand attitude, but the impact of perceived rarity is not always positive across product categories. (4) The purchase intention regarding consumer luxury brands is directly influenced by perceived esthetics, perceived orthodoxy, and perceived rarity, and indirectly influenced through a consumer's dreams. (5) Perceived esthetics and orthodoxy are considered proxy variables of SENSE, FEEL, THINK, and ACT in the SEM. Perceived rarity is considered to be related to RELATE, but not a proxy variable of RELATE because both function differently in certain cases. This is a complicated reflection of consumer reference groups, social interactions, and personalities, among other attributes.
\end{abstract}

Keywords: Luxury Brand, Customer Experience, Positioning Analysis, Consumer Attitude, Consumer Information Processing

\section{Introduction}

\subsection{Background}

In every industry, companies benchmark rivals and enter into price competition. As a result, today, commoditization has become a serious problem in every industry [1]. Even brands that have achieved differentiation find it difficult to sustain it. To maintain profitability, they often try to expand sales volume and are caught in the trap of commoditization.

Meanwhile, according to several influential consulting firms, the luxury market is expanding. For example, the Boston Consulting Group (2014) reports that global luxury market's compound annual growth rate from 2010 to 2012 was $13 \%$ [2]. Contrary to mass brands suffering from commoditization, luxury brands, such as Hermes and Louis Vuitton, achieve sufficient differentiation and acquire sustainable competitive advantages. One of their peculiarities is timelessness [3].

Preceding studies on anti-commoditization suggest the importance of differentiation by experiential marketing [1, 4 , 5,6]. According to Irisawa and Nagasawa (2011), luxury brands with sustainable competitive advantage realize differentiation by creating customer experiences[7].

Luxury brands appear to create high customer experience by adopting unique marketing strategies (hereinafter luxury strategies) and acquiring a market position irrelevant to price competition. 


\subsection{Purpose}

Luxury strategies are effective for companies planning to achieve differentiation through branding. However, most existing research is based on the Western markets. Few studies guide luxury strategies in Japan and/or China, even though the two markets are second and third largest in the world.

Thus, Kumagai and Nagasawa (2015) attempted to identify the determinants of consumer attitude toward luxury brands and a key success factor of luxury strategy (L-KSF) by conducting a marketing research in Japan and a detailed analysis of luxury brands' marketing strategies [8]. However, the study comprehensively analyzed eight luxury brands in four product categories, but did not address differences among the product categories. In addition, it does not discuss how a company's marketing activities are reflected in consumer brand attitude in consumer information processing.

Therefore, this study extends Kumagai and Nagasawa (2015) with the following two objectives:

1) Conduct a comparative analysis of consumer attitude toward luxury brands between Japanese and Chinese representative markets (Tokyo area and Shanghai city) and across the four product categories.

2) Discuss consumer perception, customer experience, and attitude toward luxury brands in consumer information processing.

In addition, it provides implications for the improvement of marketing strategies and their accuracy in Japan and China.

\subsection{Paper Structure}

Consumer perception and attitude are explored using data from an online survey and a psychological approach toward both.

In section 2-3, market research of consumer perception and attitude toward luxury brands is conducted in China's representative market, Shanghai. The results are then compared with those of consumer research in Japan [8].

In section 4, the determining factors of consumer attitude toward luxury brands in Japan and China are analyzed. These factors are further compared between countries and across product categories.

In section 5, in consumer information processing, customer experiences formed on the basis of consumer perception are discussed.

In section 6, this paper concludes with implications for companies in Japan and China that adopt luxury strategies.

\subsection{Indicators of Consumer Brand Attitude}

Luxury brand companies, such as LVMH and Richmont, have grown by fascinating all categories of consumers, and not just the opulent. Luxury brand businesses target not only the wealthy class but also non-wealthy ones [3].

Some other studies, such as Kapferer and Bastien (2009) and Katahira (1999), suggest dreams as an important factor influencing luxury branding [3,9]. That is to say, it is considered that the higher the dream level, the more favorable the attitude held by a consumer. Drawing on the literature, this study measures consumer attitude toward luxury brands on the basis of dream levels felt by various consumers.

On the other hand, no one doubts sales revenue is an important aspect for brand business. Even for companies whose key performance indicators include profit or return on equity, the source of such numbers is sales revenue. In this case, purchase intention can be an important indicator of consumer brand attitude.

Therefore, this study considers dream level and purchase intention as measures indicating various consumers' luxury brand attitude.

\subsection{Framework of Customer Experience and Information Processing}

Here, customer experience is defined as containing both actual and virtual experiences. Customer experience is considered a positive customer value and is discussed using the strategic experiential module (SEM) (Table 1), as suggested by Schmitt (1999) [4].

Table 1. Strategic experiential module.

\begin{tabular}{|c|c|}
\hline \multicolumn{2}{|c|}{ Strategic experiential module } \\
\hline Sense & Sensory experiences \\
\hline Feel & Affective experiences \\
\hline Think & Creative, cognitive experiences \\
\hline Act & Physical experiences, behaviors and lifestyles \\
\hline Relate & $\begin{array}{l}\text { Social-identity experiences that result from reference group or } \\
\text { culture }\end{array}$ \\
\hline
\end{tabular}

Note: Adopted from Schmitt (1999)

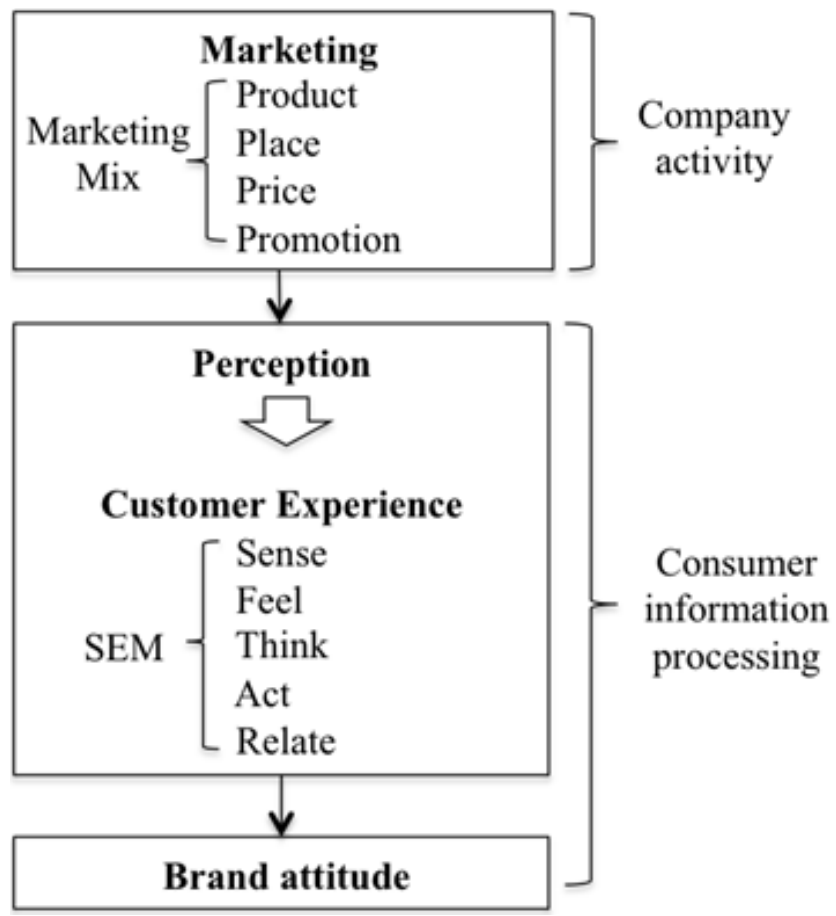

Figure 1. Formation of consumer experience and brand attitude. 
Customer experience is created through so-called "experience providers," such as communications, visuals and verbal identity, product presence, and electronic media [4]. Today, with the serious problem of commoditization, experiential marketing is considered to be an effective strategy in acquiring a competitive advantage. Therefore, one of the issues brand businesses face is customer experiences and their effects on consumer brand attitude created by marketing activities.

Figure 1 shows the process of using company marketing activities as outside stimuli to influence a consumer's mind, leading to the formation of customer experiences, and subsequently, consumer brand attitude.

\section{Consumer Research}

This section describes the method adopted to analyze consumer behavior in Japan and China and presents the results. The researched brands and perception measures are identical to those in Kumagai and Nagasawa (2015) [8].

\subsection{Researched Luxury Brands}

Equally to Kumagai and Nagasawa's (2015) research, eight brands across four product categories are researched in this paper. The researched brands are as follows.

1) Apparel: Ralph Lauren (RL) and Armani (AR)

2) Leather goods: Coach $(\mathrm{CH})$ and Louis Vuitton (LV)

3) Jewelry: Tiffany (TF) and Cartier (CT)

4) Automobile: Cadillac (CD) and Mercedes Benz (MB)

\subsection{Perception Measures}

1) Kapferer scale [10]

The Kapferer scale includes 16 perception measures of luxury: beauty of the object, excellence of the products, magic, uniqueness, tradition and know-how, creativity, sensuality of the products, feeling of exceptionality, never out of fashion, international reputation, produced by a craftsperson, long history, genius creator, belonging to a minority, very few purchasers, and at the cutting edge of fashion.

2) Overall evaluation (consumer brand attitude)

The two indictors used to measure consumer experiences and attitude toward luxury brands are dreams and purchase intentions.

\subsection{Research Method}

The research design in China is equal to that in Japan by Kumagai and Nagasawa (2015), and the results in both countries are analyzed collectively. Two of the leading research firms, Macromil and Micro United Press were appointed to conduct online survey according to Kumagai and Nagasawa's instruction.

The research method is as follows:

1) Respondents: consumers with experience of purchasing luxury goods, who live in Tokyo, Japan (Tokyo, Saitama, Kanagawa, and Chiba prefecture), or Shanghai city, China.

2) Sampling method: random sampling

3) Questionnaire method: Using an online questionnaire, respondents are asked if they have experienced the purchase of luxury goods. If yes, they are asked to describe their perception regarding the brands they are aware of by rating each item on a 7-point likert scale (1: strongly disagree, 7: strongly agree).

4) Research firm: Macromill (Japan), Micro United Press (China)

5) Period: November 2013 in Japan, May 2014 in China.

This study does not account for personal income level and actual purchase of each brand since the objective is to understand the perception of not only the wealthy class but also non-wealthy classes.

However, this process may not be effective in the case of consumers who are not interested in luxury brands. Therefore, this study is restricted to consumers who are interested in luxury brands. Their interests are confirmed by asking them to describe their experiences of purchasing any kind of luxury brand. In addition, the questionnaire is designed such that consumers are required to answer questions that are related to the brands that consumers know, because it is impossible for them to evaluate brands they are unfamiliar with.

Since the purpose of this research is to measure luxury brand perception of a wide range of consumers (even if they do not purchase and use it), content validity is considered to be secured.

\subsection{Result}

The results of this research are as follows:

1) Japan (Tokyo, Kanagawa, Chiba, and Saitama Prefectures): 314 valid responses.

2) China (Shanghai city): 152 valid responses.

(Cronbach $\alpha=.949)$

Figures 2-9 show consumer perceptions in Japan and China for the eight luxury brands in the four categories. In each category, China's relative perception is similar to that in Japan. 


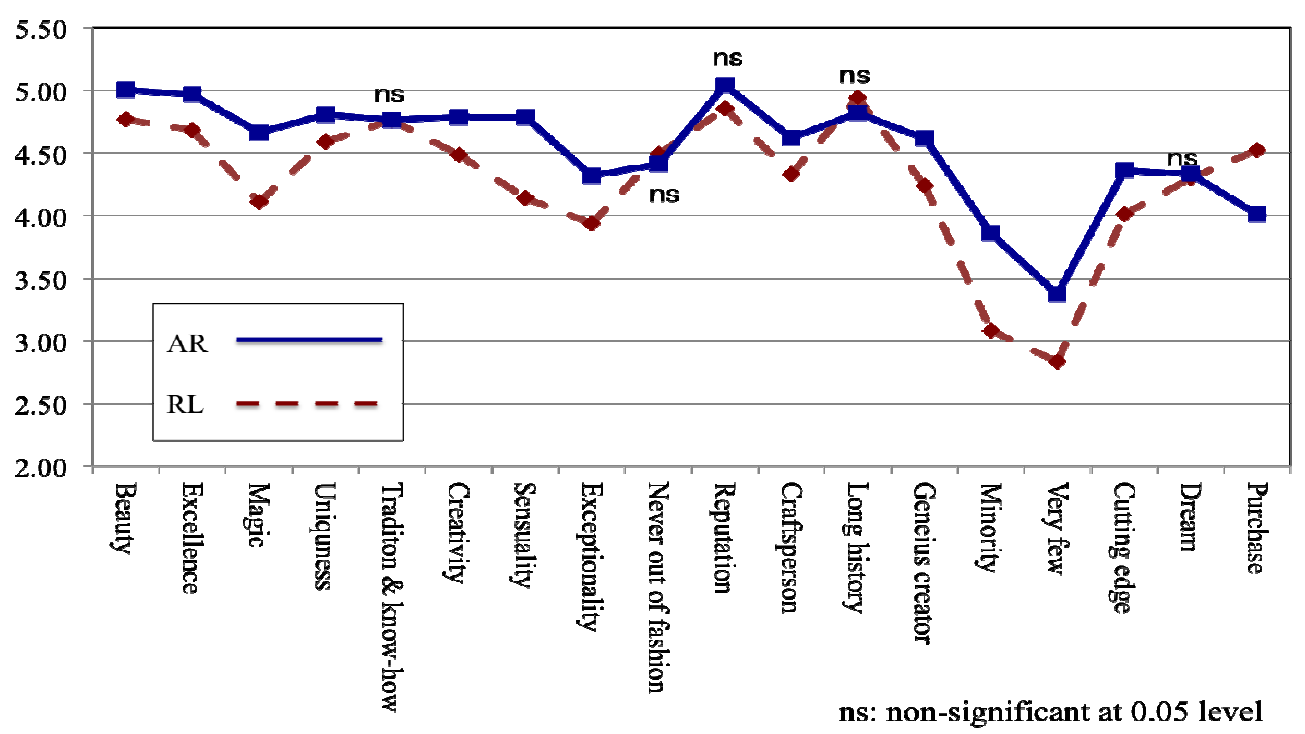

Figure 2. Perception of apparel (Japan).

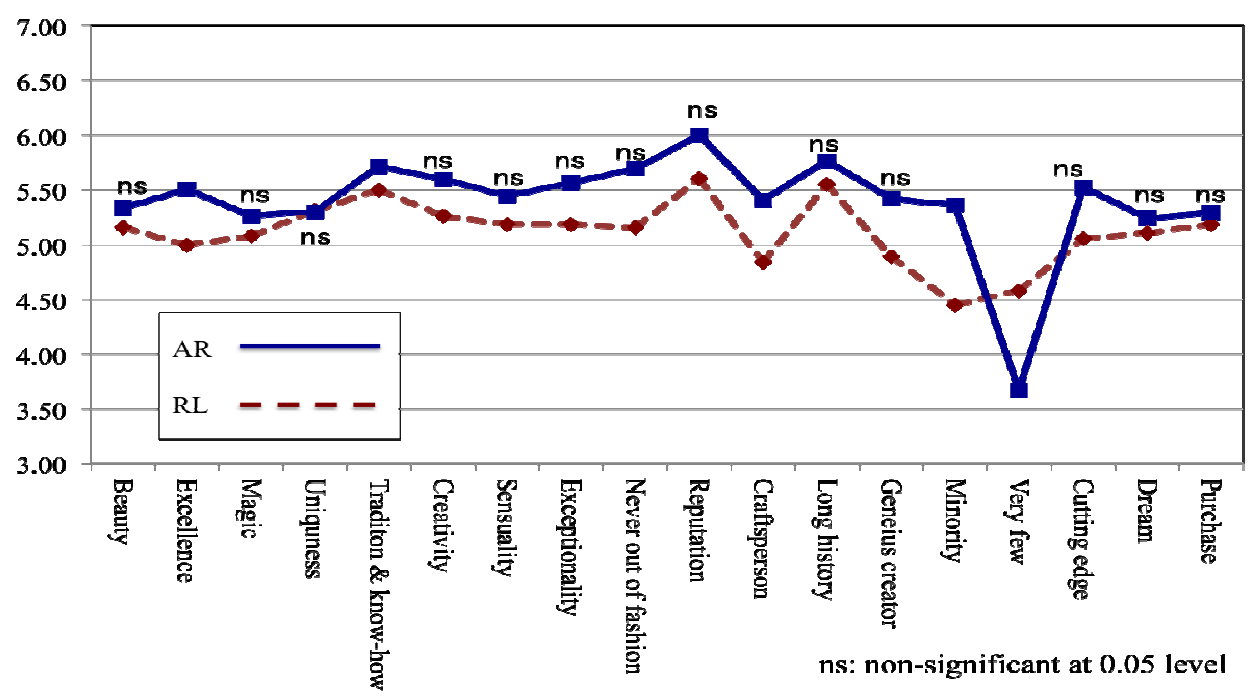

Figure 3. Perception of apparel (China)

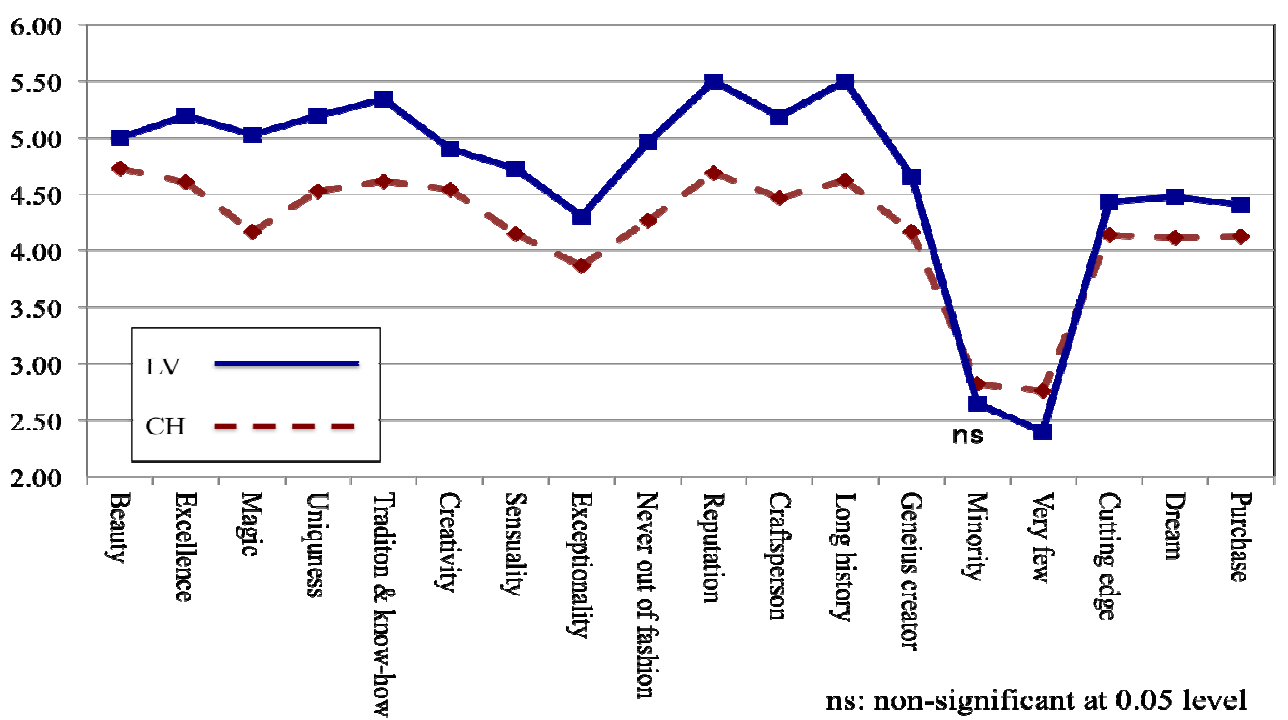

Figure 4. Perception of leather goods (Japan). 


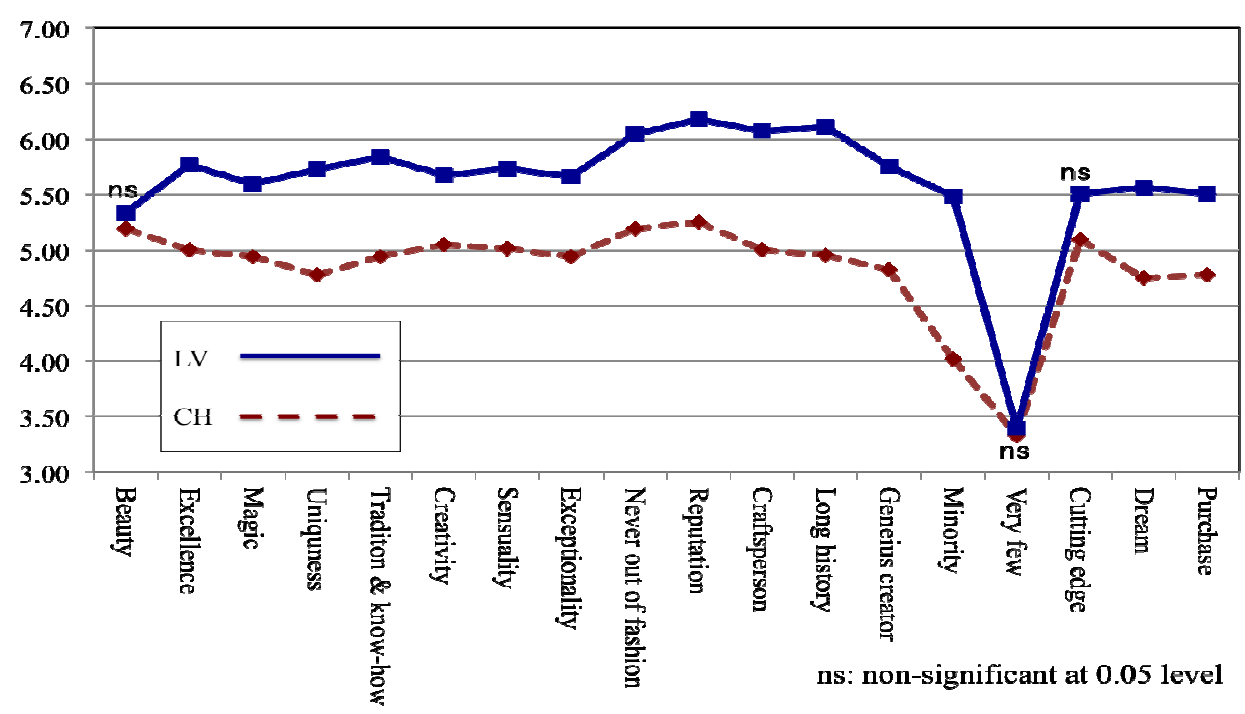

Figure 5. Perception of leather goods (China).

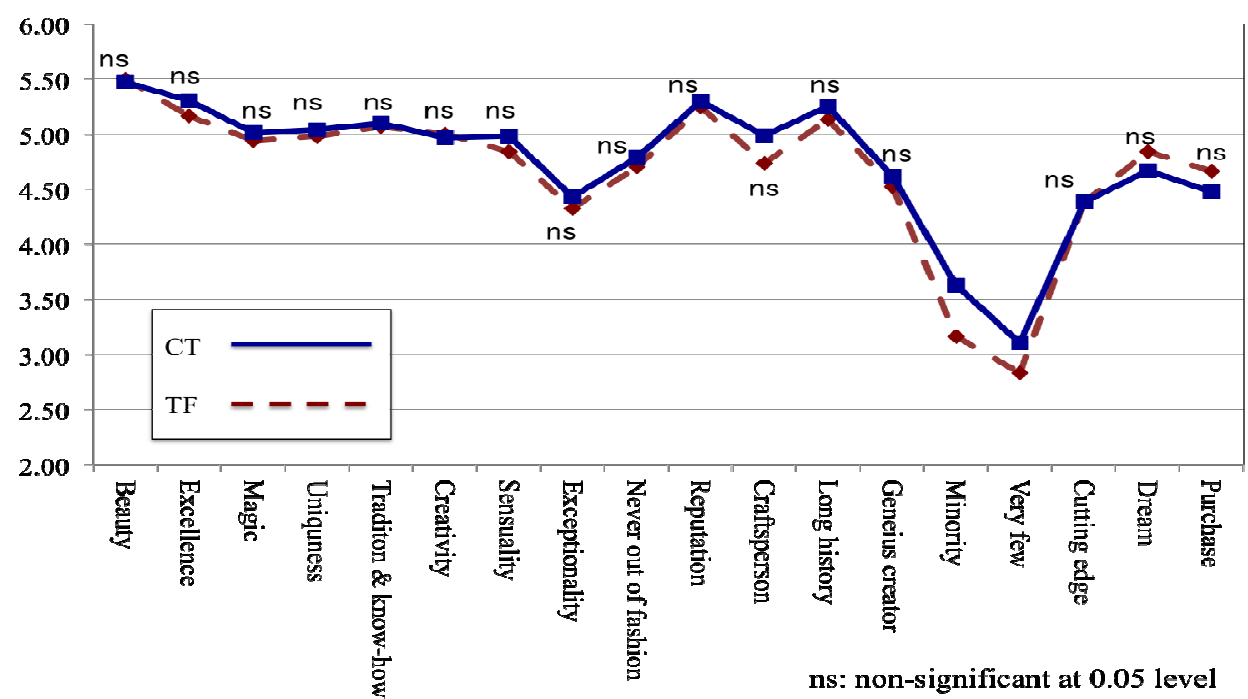

Figure 6. Perception of jewelry (Japan).

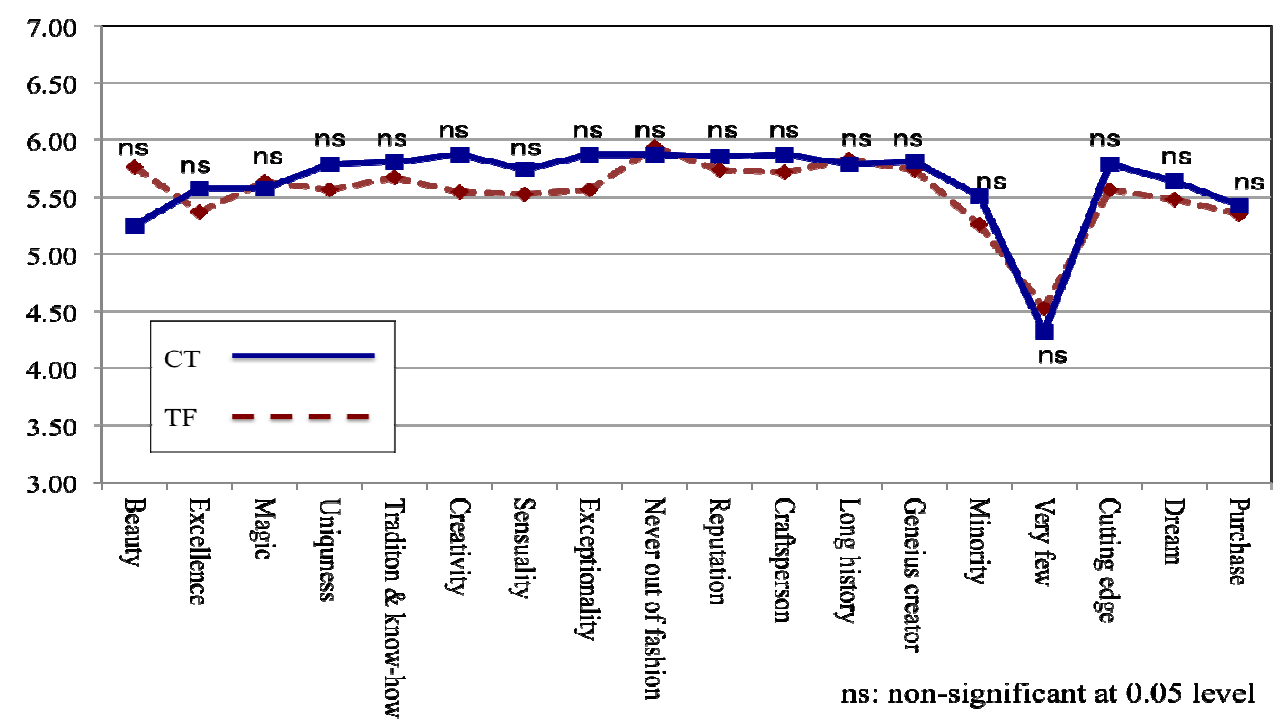

Figure 7. Perception of jewelry (China) 


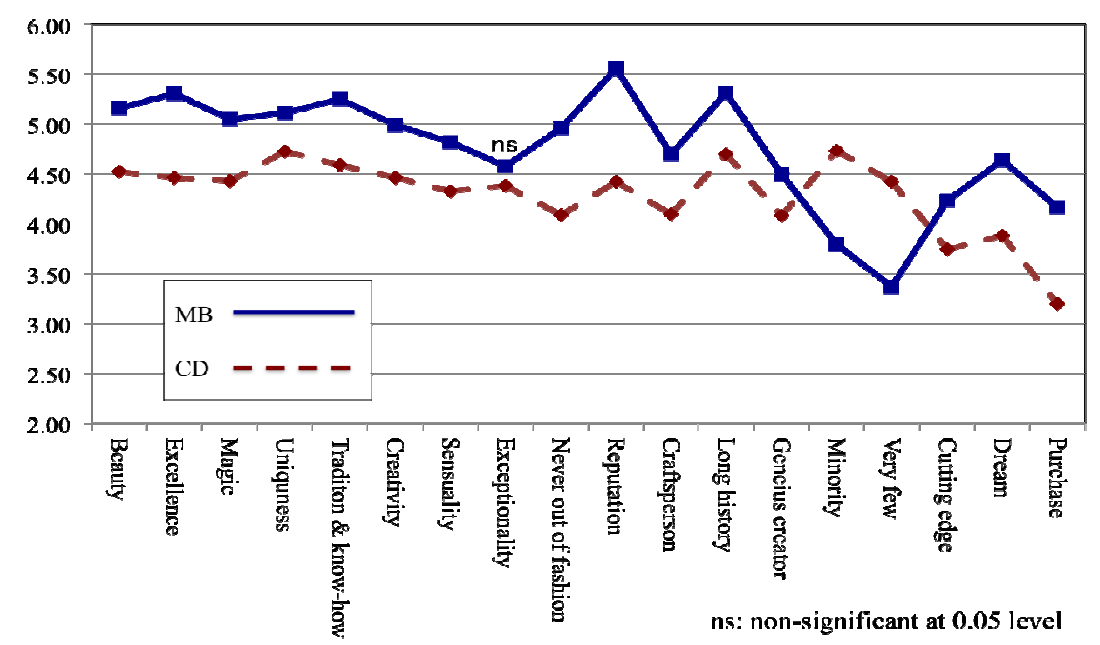

Figure 8. Perception of automobile (Japan).

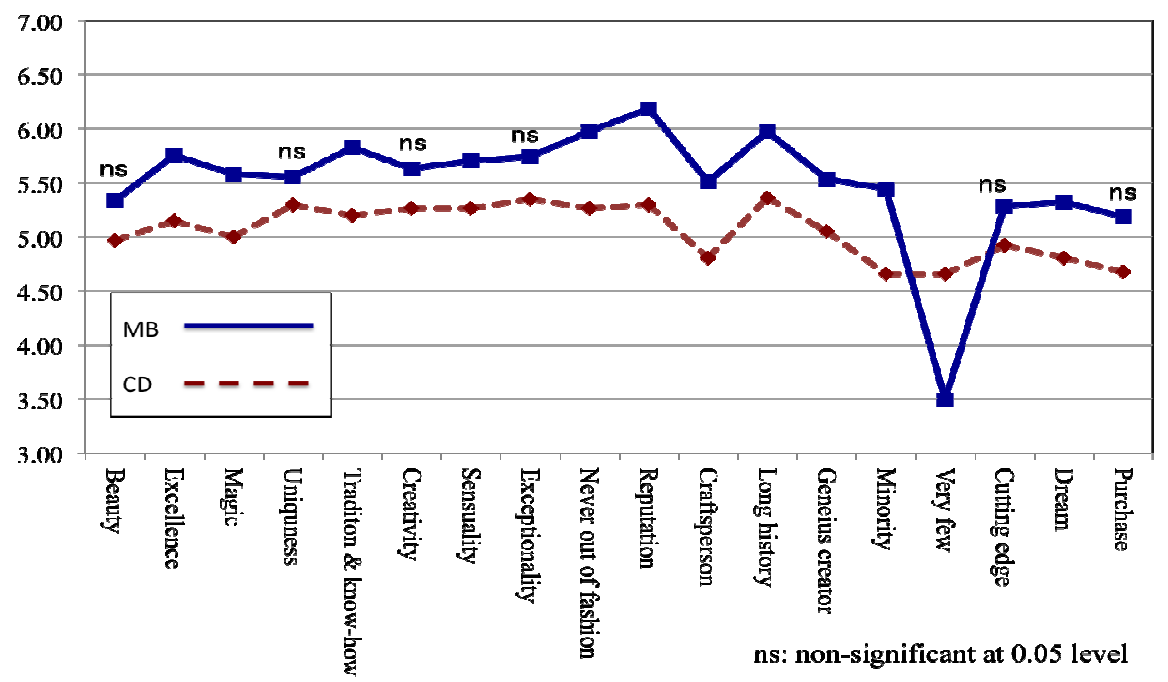

Figure 9. Perception of automobile (China)

\section{Positioning Analysis}

\subsection{Factor Analysis}

On the basis of the research results for Japan and China, 16 perceptions are summarized into small numbers of factors by factor analysis. The consumer perception research was based on 7-point likert scales, with the same scale and dimensions, and a factor analysis is conducted using the variance-covariance matrix [11] and varimax rotation. The research in Japan and China are equally conducted and the results are collectively analyzed for the purpose of a comparative analysis. The analysis reveals three factors (Tables 2-3).

Table 2. Eigen value and contribution ratio before rotation.

\begin{tabular}{llll}
\hline Factor & Eigen value & $\begin{array}{l}\text { Contribution } \\
\text { ratio }\end{array}$ & $\begin{array}{l}\text { Cumulative } \\
\text { contribution ratio }\end{array}$ \\
\hline Factor 1 & 15.255 & 54.777 & 54.777 \\
Factor 2 & 4.536 & 16.289 & 71.066 \\
Factor 3 & 1.228 & 4.41 & 75.476 \\
\hline
\end{tabular}

Table 3. Factor loading after rotation.

\begin{tabular}{llll}
\hline \multirow{2}{*}{ Perception scale } & Factor 1 & Factor 2 & Factor 3 \\
\cline { 2 - 4 } & Aesthetics & Orthodoxy & Rarity \\
\hline Excellence of the products & $\mathbf{0 . 7 4 0}$ & 0.425 & 0.051 \\
Beauty of the object & $\mathbf{0 . 7 0 4}$ & 0.325 & 0.018 \\
Magic & $\mathbf{0 . 6 8 4}$ & 0.357 & 0.195 \\
Creativity & $\mathbf{0 . 6 7 5}$ & 0.487 & 0.179 \\
Uniqueness & $\mathbf{0 . 6 7 2}$ & 0.459 & 0.147 \\
Sensuality of the products & $\mathbf{0 . 6 4 3}$ & 0.398 & 0.271 \\
Tradition and know-how & $\mathbf{0 . 6 2 7}$ & 0.569 & 0.077 \\
Long history & 0.471 & $\mathbf{0 . 6 6 0}$ & 0.071 \\
International reputation & 0.533 & $\mathbf{0 . 6 4 3}$ & 0.010 \\
Produced by a craftsperson & 0.478 & $\mathbf{0 . 6 2 2}$ & 0.180 \\
Never out of fashion & 0.482 & $\mathbf{0 . 6 0 2}$ & 0.178 \\
Belonging to a minority & 0.120 & 0.156 & $\mathbf{0 . 6 9 5}$ \\
Very few purchasers & 0.016 & -0.001 & $\mathbf{0 . 6 8 1}$ \\
Feeling of exceptionality & 0.501 & 0.421 & 0.432 \\
Genius creator & 0.489 & 0.550 & 0.298 \\
At the cutting edge of fashion & 0.435 & 0.480 & 0.292 \\
\hline Eigen Value & 4.887 & 3.676 & 1.549 \\
Contribution ratio & 30.542 & 22.976 & 9.682 \\
Cumulative contribution ratio & 30.542 & 53.518 & 63.200 \\
\hline
\end{tabular}


The 16 perceptions, their factor loading, and extracted factors are as follows:

1) Factor 1 (perceived esthetics). It mainly includes excellence of product, beauty of the object, magic, creativity, uniqueness, sensuality of the products, and tradition and know-how.

2) Factor 2 (perceived orthodoxy): It mainly reflects long history, international reputation, produced by a craftsperson, and never out of fashion.

3) Factor 3 (perceived rarity): It mainly shows belonging to minority and very few purchasers.

\subsection{Perception Map}

Brand positioning formed in a consumer's mind is analyzed using a perception map for both Japan and China.

The perception maps comprise the three factors extracted using the factor analysis (Figures 10-13).

The orthodoxy map for esthetics (Figures 10 and 11) shows that consumers in China have perceptions similar to those in Japan. On the basis of these two factors, LV, MB, CT, and $\mathrm{TF}$ received high scores, followed by AR at the mid-level, and $\mathrm{CD}$ at the lowest.

Both the Japanese and Chinese consumers assigned low ratings to $\mathrm{RL}$ and $\mathrm{CH}$ in esthetics. However, in the case of orthodoxy, the Chinese perception of RL and $\mathrm{CH}$ is lower than that of the Japanese.

The rarity map for esthetics (Figures 12 and 13) shows, in rarity, that both the Japanese and Chinese consumers gave high ratings for $\mathrm{CD}$ and low ones for $\mathrm{CH}$. Other brands received mid or low scores by Japanese consumers and high or mid scores by Chinese consumers.

In Figures 12 and 13, the esthetics score of each brand is equal to that in Figures 10 and 11.

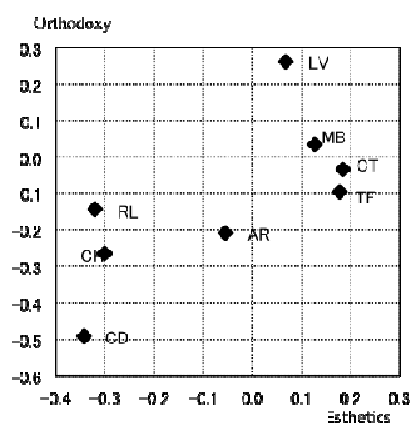

Figure 10. Esthetics-orthodoxy perception map (Japan).

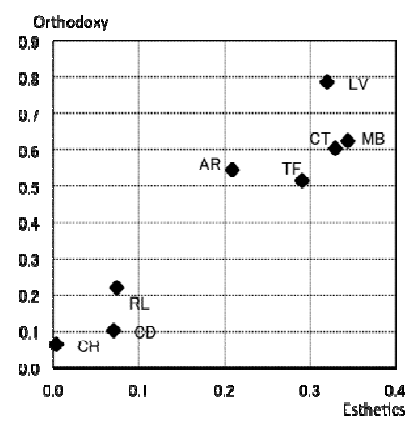

Figure 11. Esthetics-orthodoxy perception map (China).

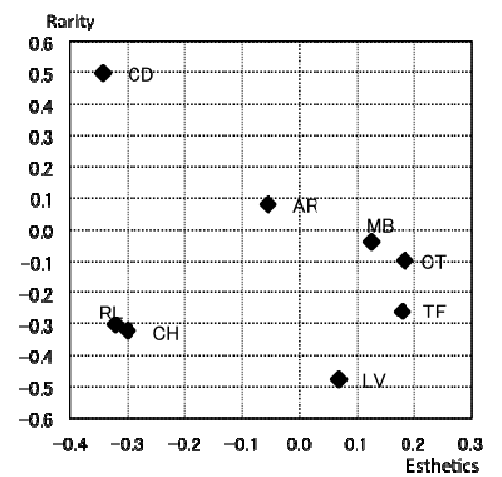

Figure 12. Esthetics-rarity perception map (Japan).

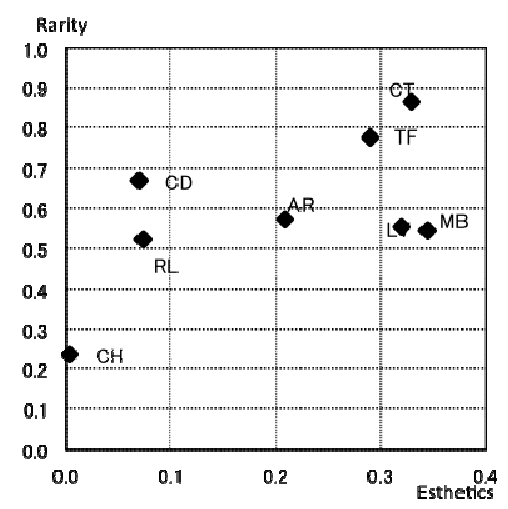

Figure 13. Esthetics-rarity perception map (China).

\section{Determinants of Consumer Brand Attitude}

\subsection{Model and Determinants of Consumer Brand Attitude}

This section analyzes the impact of the three extracted factors-perceived esthetics, perceived orthodoxy, and perceived rarity — on consumer attitude toward luxury brands using dreams and purchase intention as indicators. In addition, the impact of dreams on purchase intention is examined.

The impact of the three factors on consumer attitude and that of dreams on purchase intention are measured using a standardized partial regression coefficient.

Figure 14 shows the model.

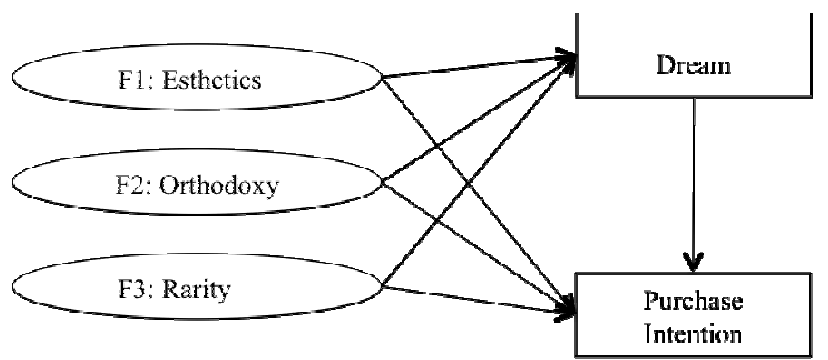

Figure 14. Model: determinants of consumer attitude toward luxury brands.

Table 4 shows the impact of the three factors on consumer attitude and Table 5 depicts the impact of dreams on purchase intention. 


\subsection{Determinants of Consumer Brand Attitude Toward the Comprehensive Luxury Category}

Concerning comprehensive consumer attitude toward luxury brands, all three factors had a similar positive impact on both Japanese and Chinese consumers' dreams.

All three factors positively impacted the Chinese consumers' purchase intention. On the other hand, only esthetics and orthodoxy affected Japanese consumers' purchase intention, whereas that of rarity was not significant.

\subsection{Determinants of Consumer Attitude Toward Luxury Brands Across Product Categories}

Consumer attitude toward luxury brands across four product categories is discussed here.

In the apparel category, all three factors positively impacted consumers' dream in both Japan and China.

On the other hand, only two factors (esthetics and orthodoxy) positively influenced consumers' purchase intentions in Japan and China. The rarity impact was not significant for consumers from both countries.

In the leather goods category, all three factors positively affected consumer dreams for both Japan and China.

Similarly, all three factors positively impacted both Japanese and Chinese consumers' purchase intention.

In the jewelry category, all three factors positively impacted Japanese and Chinese consumers' dreams.

Similarly, all three factors positively impacted Japanese and Chinese consumers' purchase intention.

In the automobile category, all three factors positively affected Chinese consumers' dreams. On the other hand, only esthetics and orthodoxy impacted Japanese consumers' dream, but the effect of rarity was not significant.

Similarly, all three factors positively impacted Chinese consumers' purchase intention, whereas only esthetics and orthodoxy affected Japanese consumers' dreams; the impact of rarity was not significant.

\subsection{Path from Dreams to Purchase Intentions}

For both Japanese and Chinese consumers, dreams strongly and positively impacted purchase intentions in the comprehensive and all four product categories.

Table 4. Standardized regression coefficient (Determinant factors $\rightarrow$ dreams and purchase intention).

\begin{tabular}{llll}
\hline Category & Determinants & Japan & China \\
\hline \multirow{2}{*}{ Comprehensive } & Esthetics & $.491^{* *}$ & $.377^{* *}$ \\
(Dream) & Orthodoxy & $.339^{* *}$ & $.348^{* *}$ \\
& Rarity & $.179^{* *}$ & $.282^{* *}$ \\
& $\mathrm{R}^{2}$ & .521 & .590 \\
Comprehensive & Esthetics & $.396^{* *}$ & $.469^{* *}$ \\
(Purchase) & Orthodoxy & $.293^{* *}$ & $.277^{* *}$ \\
& Rarity & .026 & $.271^{* *}$ \\
& $\mathrm{R}^{2}$ & .345 & .615 \\
Apparel (Dream) & Esthetics & $.441^{* *}$ & $.356^{* *}$ \\
& Orthodoxy & $.381^{* *}$ & $.375^{* *}$ \\
& Rarity & $.163^{* *}$ & $.159^{* *}$ \\
Apparel (Purchase) & Esthetics & .525 & .510 \\
\hline
\end{tabular}

\begin{tabular}{|c|c|c|c|}
\hline Category & Determinants & Japan & China \\
\hline \multirow{7}{*}{$\begin{array}{l}\text { Leather goods } \\
\text { (Dream) }\end{array}$} & Orthodoxy & $.412 * *$ & $.430 * *$ \\
\hline & Rarity & -.059 & .058 \\
\hline & $\mathrm{R}^{2}$ & .332 & .708 \\
\hline & Esthetics & $.497 * *$ & $.342 * *$ \\
\hline & Orthodoxy & $.367 * *$ & $.390 * *$ \\
\hline & Rarity & $.506^{* *}$ & $.234 * *$ \\
\hline & $\mathrm{R}^{2}$ & .590 & .598 \\
\hline \multirow{4}{*}{$\begin{array}{l}\text { Leather goods } \\
\text { (Purchase) }\end{array}$} & Esthetics & $.497 * *$ & $.496^{* *}$ \\
\hline & Orthodoxy & $.232 * *$ & $.214 * *$ \\
\hline & Rarity & $.158 * *$ & $.223 * *$ \\
\hline & $\mathrm{R}^{2}$ & .417 & .585 \\
\hline \multirow{4}{*}{ Jewelry（Dream） } & Esthetics & $.452 * *$ & $.606^{* *}$ \\
\hline & Orthodoxy & $.331 * *$ & $.239 * *$ \\
\hline & Rarity & $.223 * *$ & $.181^{*}$ \\
\hline & $\mathrm{R}^{2}$ & .481 & .560 \\
\hline \multirow{4}{*}{ Jewelry（Purchase） } & Esthetics & $.434 * *$ & $.621 * *$ \\
\hline & Orthodoxy & $.290 * *$ & $.191 * *$ \\
\hline & Rarity & $.130 * *$ & $.276^{* *}$ \\
\hline & $\mathrm{R}^{2}$ & .388 & .620 \\
\hline \multirow{4}{*}{$\begin{array}{l}\text { Automobile } \\
\text { (Dream) }\end{array}$} & Esthetics & $.513 * *$ & $.294 * *$ \\
\hline & Orthodoxy & $.298 * *$ & $.378 * *$ \\
\hline & Rarity & .056 & $.468 * *$ \\
\hline & $\mathrm{R}^{2}$ & .480 & .705 \\
\hline \multirow{4}{*}{$\begin{array}{l}\text { Automobile } \\
\text { (Purchase) }\end{array}$} & Esthetics & $.389 * *$ & $.356^{* *}$ \\
\hline & Orthodoxy & $.248 * *$ & $.306^{* *}$ \\
\hline & Rarity & -.010 & $.447 * *$ \\
\hline & $\mathrm{R}^{2}$ & .295 & .669 \\
\hline
\end{tabular}

Notes. $* \mathrm{P}<.05, * * \mathrm{P}<.01$

Table 5. Standardized regression coefficient (Dream $\rightarrow$ purchase intention).

\begin{tabular}{lll}
\hline Category & Japan & China \\
\hline Comprehensive & $.738^{* *}$ & $.819^{* *}$ \\
$\mathrm{R}^{2}$ & .544 & .671 \\
Apparel & $.731^{* *}$ & $.721^{* *}$ \\
$\mathrm{R}^{2}$ & .533 & .516 \\
Leather goods & $.766^{* *}$ & $.856^{* *}$ \\
$\mathrm{R}^{2}$ & .586 & .732 \\
Jewelry & $.735^{* *}$ & $.718^{* *}$ \\
$\mathrm{R}^{2}$ & .540 & .510 \\
Automobile & $.723^{* *}$ & $.893^{* *}$ \\
$\mathrm{R}^{2}$ & .522 & .796 \\
\hline
\end{tabular}

Notes. $* \mathrm{P}<.05, * * \mathrm{P}<.01$

\section{Customer Experience and Determinants of Consumer Brand Attitude}

As per the discussion in section 3 and 4, the three factors-perceived esthetics, perceived orthodoxy, and perceived rarity - extracted using factor analysis influence consumer attitude to some degree and are considered determinants of consumer attitude toward luxury brands.

This section discusses customer experiences formed on the basis of consumer brand perception using company marketing activities.

\subsection{Company Marketing Activity and Consumers' Perception, Brand Attitude, and Brand Experience}

Kumagai and Nagasawa (2015) conducted a detailed analysis of marketing strategies adopted by the eight luxury 
brands and identified peculiarities in brands that received high scores as per the three factors used to determine consumer brand attitude. These marketing peculiarities of highly evaluated brands fall under the L-KSF: own manufacturing, symbolic top-of-the-pyramid product, less brand expansion or upward and downward brand expansion, high price range, majestic museum-likestore, sales channel under own control, image advertising, and storytelling [8].

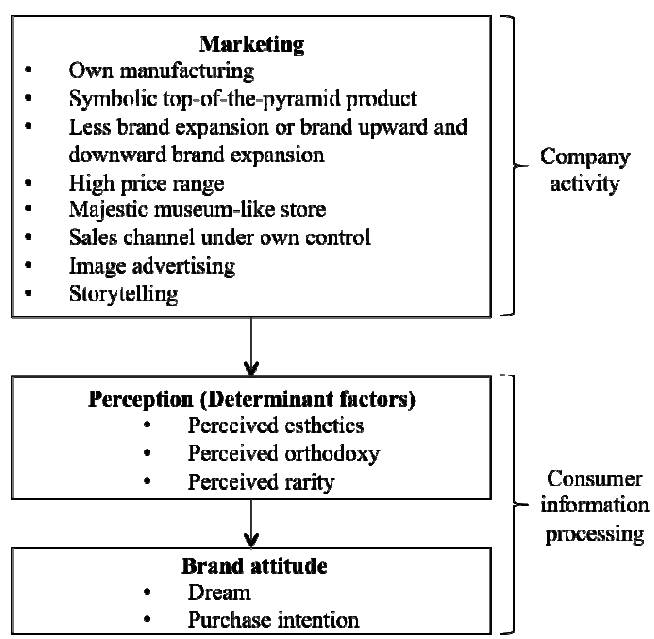

Figure 15. Formation of consumer perception and attitude toward luxury brands (Based on Kumagai and Nagasawa, 2015).

Figure 15 presents the conceptual chart of Kumagai and Nagasawa's (2015) discussion that a company's marketing activities that include these eight peculiarities impact the three factors as determinants of consumer attitude toward luxury brands, subsequently forming favorable consumer attitudes.

However, customer experience is not considered in the consumer information process (Figure 15).

In reality, not only a brand user but also a non-brand user has brand experience through various brand contact points. Thus, it is considered that customer experience is formed in a consumer's mind through perception and is reflected in a consumer's brand attitude (Figure 1).

Therefore, on the basis of the conceptual chart in Figure 1, this study now discusses what customer experience is formed in a consumer's mind using the three factors extracted from the factor analysis. Customer experiences are discussed using the SEM [4].

\subsection{Customer Experience Related to Perceived Esthetics}

Factor loading (Table 3) shows that perceived esthetics reflects the perception items of excellence of the products, beauty of the object, magic, and creativity, among others.

These items indicate products that are excellent in terms of design and quality and are considered to appeal to consumers' sense and feeling. In other words, perceived product esthetics implies a consumer feeling fascinated by the excellent product design, quality, or beauty.

Thus, it is considered that the customer experience of SENSE and FEEL in the SEM are formed in a consumer's mind when product esthetics is perceived.

Moreover, it is considered that the customer experience of ACT is formed because consumer behavior changes when using a brand product with high esthetics.

Therefore, perceived esthetics as a determinant of consumer attitude toward luxury brands is considered a proxy variable of SENSE, FEEL, and ACT.

\subsection{Customer Experience Related to Perceived Orthodoxy}

Factor loading (Table 3) shows that perceived orthodoxy reflects the perception items of long history, international reputation, produced by a craftsperson, and never out of fashion, among others.

These items show brand root, manufacturing background, and brand story and are considered to appeal to consumers' intelligence. That is, perceived luxury orthodoxy implies that a consumer is fascinated by the luxury brand's history or story.

In other words, it is considered that the customer experience of THINK in the SEM is formed in the consumers mind when they perceive luxury orthodoxy.

In addition, the customer experience of ACT is said to form because consumer behavior changes when using a brand product with high orthodoxy.

Thus, perceived orthodoxy as a determinant of consumer attitude toward a luxury brand is considered a proxy variable of THINK and ACT.

\subsection{Customer Experience Related to Perceived Rarity}

Factor loading (Table 3) shows that perceived rarity reflects the perception items of belonging to minority and very few purchasers.

These items show low popularity in the society to which consumers belong and are considered to influence consumer psychology through reference groups.

However, as analysis of determinants (Table 4) shows that perceived rarity does not always positively impact consumer attitude. In some cases, the consumer may be excited to use a rare brand product because of the potential snob value; however, in other cases, consumers may feel uncomfortable to use a rare brand product because they may stand out unfavorably.

That is, the impact of perceived rarity on consumer attitude differs by brand, product category, reference group, and consumer personality.

Therefore, perceived brand rarity is considered to be related to the customer experience of RELATE; however, RELATE is a positive customer value, while the impact of perceived rarity tends to vary.

Similarly, it is considered that consumer behavior changes when using a brand with high rarity, although such a change is not always considered to be positive.

Thus, it is difficult to state whether perceived rarity as a determinant of consumer attitude toward luxury brands is a proxy variable of RELATE and ACT, although they are related to each other. 


\subsection{Customer Experience and Perception Toward Luxury Brands}

Considering the discussion above, the relationship between customer perception and experience is shown in Table 6 .

Table 6. Perception - SEM deployment.

\begin{tabular}{|c|c|c|c|c|c|}
\hline \multirow{2}{*}{ Extracted factors } & \multicolumn{5}{|c|}{ Customer experience (SEM) } \\
\hline & Sense & Feel & Think & Act & Relate \\
\hline Perceived esthetics & + & + & & + & \\
\hline Perceived orthodoxy & & & + & + & \\
\hline Perceived rarity & & & & \pm & \pm \\
\hline
\end{tabular}

\begin{tabular}{|c|c|}
\hline \begin{tabular}{l}
\multicolumn{1}{c}{ Marketing } \\
-
\end{tabular} & - Company \\
\hline \begin{tabular}{ll}
\multicolumn{1}{c}{ Perception } & \multicolumn{1}{c}{ Customer experience } \\
Perceived Esthetics & Sense, Feel, Act \\
Perceived Orthoduxy & - Think, Act \\
Perceived Rarity & ---- Act, Relate
\end{tabular} & $\begin{array}{l}\text { Consumer } \\
\text { information }\end{array}$ \\
\hline \begin{tabular}{ll} 
& \multicolumn{1}{c}{} \\
& Brand attitude \\
- & Dream \\
& Purchase intention
\end{tabular} & \\
\hline
\end{tabular}

Figure 16. Formation of consumer attitude toward and experience of luxury brands.

\section{Implications and Conclusions}

This section presents the implications of this consumer research based in Japan and China, and discussions in this paper.

\subsection{Japanese and Chinese Consumer Perceptions of Luxury Brands are Generally Similar}

Although in the brand business society, Chinese consumers' understanding about luxury brands is viewed to be in the stage of development and has not yet matured [12], their perceptions appear similar to those of Japanese consumers, particularly in the case of the eight brands analyzed in this study (Figures 2-9).

The effects of each brand's global marketing communications are considered similar for consumers in both markets.

At least in the case of Tokyo and Shanghai, brand managers can assume that consumer brand understanding in both markets is similar.

\subsection{Consumer Attitude Toward Luxury Brands can be Explained Using the Three Factors and the Impact of Perceived Rarity Differs Between Japan and China}

As for comprehensive luxury perception, perceived rarity positively impacts Chinese consumers' attitude, dreams, and purchase intentions, where as in the case of Japanese consumers', it affects only dreams, not purchase intentions.

This shows that Japanese consumers tend to care more about social risk. Thus, brand managers should care about social congruity [13], especially for Japanese consumers. By contrast, it may be better for brand managers to strengthen rarity when marketing for Chinese consumers.

\subsection{Across Product Categories, Perceived Esthetics and Orthodoxy Positively Impact Consumer Attitude, Whereas Perceived Rarity has Varying Effects}

This study found that perceived rarity does not significantly impact purchase intention in the comprehensive luxury, apparel, and automobile categories, and dreams in the automobile category. Meanwhile, rarity positively impacts both dreams and purchase intentions in the leather goods and jewelry categories.

Thus, brand managers should care about the possible varying impacts of the determinants of consumer attitude not only between markets but also across product categories.

\subsection{Purchase Intention is Impacted Directly by the Three Factors and Indirectly Through Dreams}

The determinants of purchase intention and those of dreams are not completely equal; however, dreams are said to positively impact purchase intention.

Therefore, brand managers should care about purchase intention as well as dreams. This analysis suggests that dream rising can result in higher sales.

\subsection{Customer Experience Formed in Consumers' Mind can be Partly Explained Using Proxy Variables for Consumer Perceptions}

In the SEM, perceived esthetics is considered a proxy variable of SENSE, FEEL, and ACT and perceived orthodoxy is considered a proxy variable of THINK and ACT.

However, perceived rarity is not considered a proxy variable of RELATE and ACT because the impact of rarity is not always the same as the positive effect customer experience can have on consumer brand attitude, although they are assumed to be closely related.

In this study, the impact of perceived rarity sometimes differs between Japanese and Chinese consumers. This suggests the possible impact of customer experience and that RELATE could be perceived differently between both countries.

When conducting global marketing strategies, brand managers should consider the meaning of customer experiences of RELATE while accounting for cultural backgrounds or social interactions between the countries.

\subsection{Rarity Management and Customer Experience of RELATE}

Thus far, the discussion has evidenced the difficulty of 
rarity management in luxury brand strategies.

Some studies describe the rarity management of luxury brand businesses.

For example, Dubois and Paternault (1995) propose a "dream formula" that describes consumer dreams as a negative function of consumer purchase (in other words, a positive function of rarity) and that their relationship is linear.[14].

On the other hand, Kapferer (2012)shows three types of relationships between consumer perception of a brand as a luxury and brand penetration (Figure 17) [15].

In this paper, perceived rarity does not always have a positive impact on consumers' attitude of luxury brands, which supports Kapferer's (2012) view. It also addresses the band wagon effect and snob effect in discussing consumer behavior, which is in line with preceding studies.

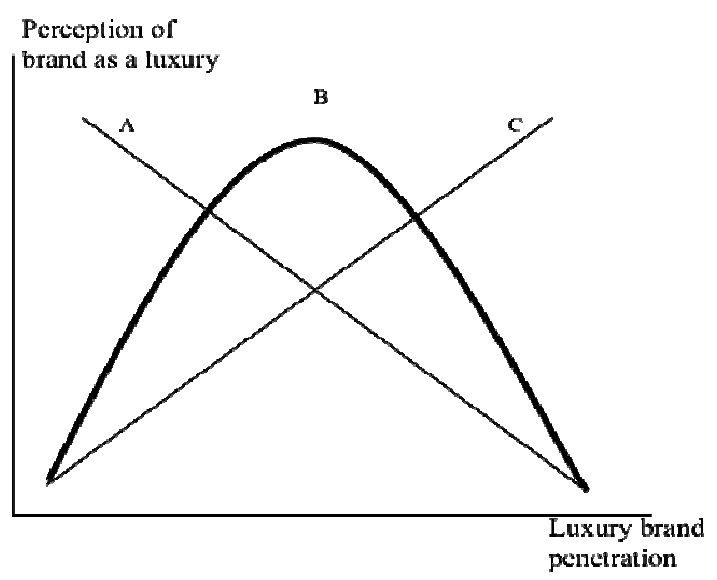

Figure 17. Luxury-rarity relationship (Kapferer 2012).

\subsection{Limitations}

This paper extends Kumagai and Nagasawa's (2015) research in Japan and conducts a consumer research in China. It analyzes and discusses the determinants of consumer attitude toward luxury brands across four product categories in both countries. The implications have been discussed in section 6 .

However, this study still poses the following limitations, which are left for future research on luxury customer experience.

1) Consumer perception and attitude is researched for only eight brands across four product categories. For the sake of generalization, it is necessary to conduct a much wider research.

2) Consumer research is performed in only two markets. This makes it difficult generalize the findings across consumer attitudes globally.

3) The relationship between consumer perception and SEM is not perfect. Thus, more suitable perception measures should be discussed for empirical research on customer experience.
4) Finally, rarity management is not researched for consumer attributes, product attributes, and contexts. A cluster analysis or contingency approach is desirable.

\section{References}

[1] Onzo N. (2007) Marketing Strategies against Commoditization, Yuhikaku.

[2] Abtan O., Achille A., Bellaiche J., Kim Y., Lui V., Mall A., Meu-pochtter A., Willersdorf A. (2014) Shock of the New Chic: Dealing with New Complexity in the Business of Luxury, Boston Consulting Group.

[3] Kapferer J. N. and Bastien V. (2009) The Luxury Strategy, Kogan Page.

[4] Schmitt B. H. (1999) Experiential Marketing,Journal of marketing management, 15(1-3), pp.53-67.

[5] PineB. J. and Gilmore J. H. (1999) The Experience Economy, Harvard School Press.

[6] Nagasawa S. (Ed.) (2005) Value Creation through Customer Experience that Enables to Develop Hit Products: Fabrication that Influencing on Human Kansei, Nikkagiren.

[7] Irisawa Y.and Nagasawa S. (2011) Conditions of Luxury Branding in Japanese and French Brand Company: Case Study and Comparative Analysis for the Condition of Constructing Brand,Journal of Japan Association of Product Development and Management, 8(1), pp.34-51.

[8] Kumagai K. and Nagasawa S. (2015)Observation of Luxury Brands' Perceived Position and their Key Success Factor (L-KSF) in the Japanese Market, Transactions of Japan Society of Kansei Engineering, Vol.14 (to be published in April 2015).

[9] Katahira H. (1999) Principals of Power Brands, Diamond Inc.

[10] Kapferer J. N. (1998) Why Are We Seduced by Luxury Brands?, Journal of Brand Management, 6(1), pp. 44-49.

[11] Kanda N., Ofuji T., Okamoto T., Konno T., Nagasawa S. (2000) The Seven Tools for New Product Planning-System for new Product Development, Nikkagiren.

[12] Yo A. (2005) China Changes to Great Brand Consuming Market, Japan Consumer Marketing Research Institute.

[13] Sirgy M.J. (1985) Using Self-Congruity and Ideal Congruity to Predict Purchase Motivation, Journal of Business Research 13, pp.195-206.

[14] Dubois B. and Paternault C. (1995) Observations: Understanding the World of International Luxury Brands: The Dream Formula, Journal of Advertising Research, July/August, 1995.

[15] Kapferer J. N. (2012) Abundant Rarity: The Key to Luxury G, Business Horizons, 55, pp.453-462. 